\title{
Substrate geometry directs the in vitro mineralization of calcium phosphate ceramics
}

Citation for published version (APA):

Bianchi, M., Edreira, E. R. U., Wolke, J. G. C., Birgani, Z. T., Habibovic, P., Jansen, J. A., Tampieri, A., Marcacci, M., Leeuwenburgh, S. C. G., \& van den Beucken, J. J. J. P. (2014). Substrate geometry directs the in vitro mineralization of calcium phosphate ceramics. Acta Biomaterialia, 10(2), 661-669. https://doi.org/10.1016/j.actbio.2013.10.026

Document status and date:

Published: 01/02/2014

DOI:

10.1016/j.actbio.2013.10.026

Document Version:

Publisher's PDF, also known as Version of record

Document license:

Taverne

Please check the document version of this publication:

- A submitted manuscript is the version of the article upon submission and before peer-review. There can be important differences between the submitted version and the official published version of record.

People interested in the research are advised to contact the author for the final version of the publication, or visit the DOI to the publisher's website.

- The final author version and the galley proof are versions of the publication after peer review.

- The final published version features the final layout of the paper including the volume, issue and page numbers.

Link to publication

\footnotetext{
General rights rights.

- You may freely distribute the URL identifying the publication in the public portal. please follow below link for the End User Agreement:

www.umlib.nl/taverne-license

Take down policy

If you believe that this document breaches copyright please contact us at:

repository@maastrichtuniversity.nl

providing details and we will investigate your claim.
}

Copyright and moral rights for the publications made accessible in the public portal are retained by the authors and/or other copyright owners and it is a condition of accessing publications that users recognise and abide by the legal requirements associated with these

- Users may download and print one copy of any publication from the public portal for the purpose of private study or research.

- You may not further distribute the material or use it for any profit-making activity or commercial gain

If the publication is distributed under the terms of Article $25 \mathrm{fa}$ of the Dutch Copyright Act, indicated by the "Taverne" license above, 


\title{
Substrate geometry directs the in vitro mineralization of calcium phosphate ceramics
}

\author{
Michele Bianchi $^{\text {a,b }}$, Eva R. Urquia Edreira ${ }^{\mathrm{b}}$, Joop G.C. Wolke ${ }^{\mathrm{b}}$, Zeinab T. Birgani ${ }^{\mathrm{c}}$, Pamela Habibovic ${ }^{\mathrm{c}}$, \\ John A. Jansen ${ }^{\mathrm{b}}$, Anna Tampieri ${ }^{\mathrm{d}}$, Maurilio Marcacci ${ }^{\mathrm{a}}$, Sander C.G. Leeuwenburgh ${ }^{\mathrm{b}}$, \\ Jeroen J.J.P. van den Beucken ${ }^{\mathrm{b}, *}$ \\ a Laboratory of NanoBiotechnology (NaBi), Istituto Ortopedico Rizzoli, via di Barbiano 1/10, 40139 Bologna, Italy \\ ${ }^{\mathrm{b}}$ Department of Biomaterials, Radboud University Medical Center, 309 Dentistry, PO Box 9101, 6500 HB Nijmegen, The Netherlands \\ ${ }^{\mathrm{c}}$ Department of Tissue Regeneration, MIRA Institute of Biomedical Technology E Technical Medicine, University of Twente, NL-7500 AE Enschede, The Netherlands \\ ${ }^{\mathrm{d}}$ Laboratory of Bioceramics and Bio-hybrid Composites, Institute of Science and Technology for Ceramics, National Research Council, Via Granarolo 64, 48018 Faenza, Italy
}

\section{A R T I C L E I N F O}

\section{Article history:}

Received 4 July 2013

Received in revised form 20 September 2013

Accepted 23 October 2013

Available online 31 October 2013

\section{Keywords:}

Calcium phosphates

Hydroxyapatite

$\beta$-Tricalcium phosphate, Concavities

Mineralization

\begin{abstract}
A B S T R A C T
Repetitive concavities on the surface of bone implants have recently been demonstrated to foster bone formation when implanted at ectopic locations in vivo. The current study aimed to evaluate the effect of surface concavities on the surface mineralization of hydroxyapatite (HA) and $\beta$-tricalcium phosphate $(\beta-\mathrm{TCP})$ ceramics in vitro. Hemispherical concavities with different diameters were prepared at the surface of HA and $\beta$-TCP sintered disks: $1.8 \mathrm{~mm}$ (large concavity), $0.8 \mathrm{~mm}$ (medium concavity) and $0.4 \mathrm{~mm}$ (small concavity). HA and $\beta$-TCP disks were sintered at 1100 or $1200^{\circ} \mathrm{C}$ and soaked in simulated body fluid for 28 days at $37^{\circ} \mathrm{C}$; the mineralization process was followed by scanning electron microscopy, energy-dispersive spectroscopy, $\mathrm{X}$-ray diffraction and calcium quantification analyses. The results showed that massive mineralization occurred exclusively at the surface of HA disks treated at $1200{ }^{\circ} \mathrm{C}$ and that nucleation of large aggregates of calcium phosphate started specifically inside small concavities instead of on the planar surface of the disks. Regarding the effect of concavity diameter size on surface mineralization, it was observed that small concavities induce 124- and 10-fold increased mineralization compared to concavities of large or medium size, respectively. The results of this study demonstrated that (i) in vitro surface mineralization of calcium phosphate ceramics with surface concavities starts preferentially within the concavities and not on the planar surface, and (ii) concavity size is an effective parameter to control the spatial position and extent of mineralization in vitro.
\end{abstract}

(c) 2013 Acta Materialia Inc. Published by Elsevier Ltd. All rights reserved.

\section{Introduction}

Commonly employed biomaterials in bone tissue engineering and regenerative medicine include bioactive ceramics and glasses, natural and synthetic polymers and composites thereof [1]. In particular, calcium orthophosphates (CaPs) are the most widely investigated materials for the substitution of lost or damaged hard tissue due to their similarity to the inorganic phase of bone, as well as having excellent biocompatibility and bioactivity [2-4]. Notably, several CaPs recently were demonstrated to exhibit osteoinductive capacity, i.e. the ability to induce bone tissue formation at an ectopic location, which in turn requires the differentiation of osteoprogenitor cells into bone-forming osteoblasts [5-7].

CaPs are available in a number of chemical compositions and crystalline phases, among which hydroxyapatite (HA), $\beta$-tricalcium

\footnotetext{
* Corresponding author. Tel.: +31 24 3667305; fax: +31243614657.

E-mail address: j.vandenbeucken@dent.umcn.nl (J.J.J.P. van den Beucken).
}

phosphate ( $\beta$-TCP) and biphasic HA/TCP ceramics are the most common for bone replacement. The bioactivity of these CaPs is strongly related to their solubility in the physiological environment, which increases with increasing amount of $\beta$-TCP (i.e. $\beta$-TCP > biphasic CaP > HA) [2]. In addition to compositional effects, surface morphologies have been shown to affect biological performance $[8,9]$. It is now clear that micro- and nanoscale morphologies of the CaP surface can strongly influence osteoblast and stem cell adhesion, proliferation and differentiation [10-12]. Ripamonti and co-workers have extensively investigated the osteogenic effect of repetitive surface concavities on either bulk ceramics [13] or CaP-coated titanium implants [14]. The starting hypothesis for these studies was that concavities, by resembling the hemi-osteon trench observable at different stages of osteoclastogenesis, are able to initiate the ripple-like cascade of bone induction and morphogenesis [15]. Ripamonti and co-workers in fact found that the presence of concavities (diameter 800$1600 \mu \mathrm{m}$, depth $400-800 \mu \mathrm{m}$ ) affected the osteoinductive capacity notably without the need for exogenous osteogenic soluble 
molecules [13]. More recently, Scarano et al. [16] showed that $500 \times 500 \mu \mathrm{m}$ hemispherical concavities prepared at the surface of CaP-coated titanium implants inserted into the tibias of rabbits led to a significant increase in bone formation inside the concavities compared to the convex areas.

Despite this increasing number of in vivo studies demonstrating a positive effect of concavities on osteogenesis, no attempts have been carried out to rationalize the mineralization process through in vitro tests. Consequently, the aim of the current study was to evaluate the role of concavities on the in vitro mineralization of different bioceramic materials. To this end, HA and $\beta$-TCP disks were prepared with hemispherical concavities of different diameters and sintered at 1100 or $1200{ }^{\circ} \mathrm{C}$. Mineralization at the surface of these bioceramic disks upon immersion in simulated body fluid (SBF) for up to 28 days was assessed by means of scanning electron microscopy (SEM), energy-dispersive spectroscopy (EDS), X-ray diffraction (XRD) and calcium quantification assays. Our starting hypotheses were that: (i) concavities prepared at the surface of bioceramic disks could effectively guide the surface mineralization process in vitro; and (ii) concavity size represents a key parameter for controlling the extent of surface mineralization in vitro.

\section{Materials and methods}

\subsection{Fabrication of heat-treated calcium phosphate disks}

The HA starting powder used in this study was obtained from a commercial source (Merck, Germany). It had a Ca/P molar ratio of 1.67, contained $\mathrm{Al}, \mathrm{Fe}, \mathrm{Mg}$ and $\mathrm{Mn}$ as the main impurities, and had a specific surface area $\left(S_{\mathrm{BET}}\right)$ of $73 \mathrm{~m}^{2} \mathrm{~g}^{-1}$ and a particle size distribution of around 3-4 $\mu \mathrm{m}$. The $\beta$-TCP was obtained from a commercial source (CAM Bioceramics BV, The Netherlands). This $\beta$-TCP powder had a $\mathrm{Ca} / \mathrm{P}$ ratio of 1.5 , contained $\mathrm{Mg}$ as the main impurity, and had a value of $S_{\mathrm{BET}}$ of $60 \mathrm{~m}^{2} \mathrm{~g}^{-1}$ and a particle size distribution of around $30 \mu \mathrm{m}$. Ceramic disks were prepared from these two powder source materials. Powders were uniaxially pressed at $103 \mathrm{MPa}$ $(15,000 \mathrm{psi})$ for $10 \mathrm{~min}$ in a cylindrical steel mold (internal diameter $\sim 21 \mathrm{~mm}$ ). Subsequently, cylindrical HA and $\beta$-TCP green ceramics were heat-treated in a furnace at $800^{\circ} \mathrm{C}$ for $6 \mathrm{~h}\left(1.67{ }^{\circ} \mathrm{C} \mathrm{min}^{-1}\right)$ to provide suitable strength to the ceramic to withstand the stresses applied during the machining process. Subsequently, heat-treated HA and $\beta$-TCP cylinders were cut into disks (thickness $\sim 4 \mathrm{~mm}$, diameter $\sim 21 \mathrm{~mm}$ ).

\subsection{Role of chemical composition and sintering temperature on mineralization process}

For a preliminary evaluation of the role of chemical composition and sintering temperature on the onset of the mineralization process, drill tips with different diameter sizes $(2.1,1$ and $0.5 \mathrm{~mm}$; Horico, Germany) were used to prepare the hemispherical concavities (four of each diameter) at the surface of heat-treated HA and $\beta$-TCP disks (Table 1 and Fig. 1a) with diameters of $1.8 \mathrm{~mm}$ (large concavities), $0.8 \mathrm{~mm}$ (medium concavities) and $0.4 \mathrm{~mm}$ (small concavities). The center-to-center distance between similar concavities was set at twice the concavity diameter in order to display the maximum number of concavities on the same disk while minimizing possible mutual effects on the deposition of calcium phosphate. Subsequently, the disks were sintered in a furnace for $6 \mathrm{~h}\left(1.67^{\circ} \mathrm{C} \mathrm{min}^{-1}\right)$ at either $1100^{\circ} \mathrm{C}$ (HA11_LMS and TCP11_LMS; LMS: large, medium and small concavities) or $1200{ }^{\circ} \mathrm{C}$ (HA12_LMS and TCP12_LMS).

The average crystallite size of the CaP ceramics was calculated using the Scherrer formula and the full width at half maximum of the (002) reflection of apatitic depositions. Lanthanium hexaboride (LaB6; NIST standard reference material \#660) was employed to determine the instrumental broadening under similar measuring conditions.

Freshly prepared, filter-sterilized simulated body fluid (SBF; $\mathrm{pH}$ 7.4, ionic composition: $142.0 \mathrm{mM} \mathrm{Na}+5.0 \mathrm{mM} \mathrm{K}, 1.5 \mathrm{mM} \mathrm{Mg}^{2+}$, $2.5 \mathrm{mM} \mathrm{Ca}^{2+}, 147.8 \mathrm{mM} \mathrm{Cl}^{-}, 4.2 \mathrm{mM} \mathrm{CO}_{3}{ }^{2-}, 1.0 \mathrm{mM} \mathrm{HPO}_{4}{ }^{2-}$ and $0.5 \mathrm{mM} \mathrm{SO}_{4}{ }^{2-}$ ) was used to assess the surface mineralization capacity of the experimental CaP disks [17]. HA and $\beta$-TCP disks ( $n=3$ for each experimental group) were transferred into 6-well plates and immersed in SBF solution $(10 \mathrm{ml}$ per well) for 7,14 , 21 and 28 days. The plate was kept at $37^{\circ} \mathrm{C}$ and shaken moderately $(1 \mathrm{~Hz})$. Additionally, controls $(n=3)$ consisting of empty wells filled with only SBF were used for each time point in order to detect any homogeneous nucleation in the solution or heterogeneous nucleation on the walls of well plates. The SBF was changed daily, and the supernatant was collected to determine calcium levels using the ortho-cresolphthalein complexone (Sigma-Aldrich) method. To this end, $100 \mu \mathrm{l}$ of the supernatant was mixed with $100 \mu \mathrm{l}$ of $1 \mathrm{~N}$ acetic acid (Boom BV, Meppel, The Netherlands) and incubated overnight on a shaking table. Calcium concentrations were calculated with respect to the controls (empty wells) and averaged for three samples per group. At 7, 14, 21 and 28 days, disks were removed from the SBF, gently washed with distilled water and dried at $40{ }^{\circ} \mathrm{C}$ for $24 \mathrm{~h}$.

\subsection{Role of concavity dimension on mineralization process onset}

For the quantitative evaluation of the effect of concavity size on the mineralization process, a different surface geometry was adopted: 12 concavities of $1.8,0.8$ or $0.4 \mathrm{~mm}$ diameter were prepared on the surface of HA green ceramic disks heat-treated at $800{ }^{\circ} \mathrm{C}$ (Table 1 and Fig. 1b). The center-to-center distance was set at $4 \mathrm{~mm}$ in order to maximize the distance between adjacent concavities. Finally, disks were sintered for $6 \mathrm{~h}$ at $1200{ }^{\circ} \mathrm{C}$ $\left(1.67{ }^{\circ} \mathrm{C} \mathrm{min}^{-1}\right)$. For surface mineralization experiments, two HA12 disks containing 12 surface concavities of large (HA12_L), medium (HA12_M) or small diameter (HA12_S) were immersed

Table 1

Overview of the experimental setup.

\begin{tabular}{|c|c|c|c|c|c|c|}
\hline Study & $\begin{array}{l}\text { Calcium phosphate } \\
\text { ceramics investigated }\end{array}$ & $\begin{array}{l}\text { Concavity } \\
\text { dimension } \\
\text { investigated }\end{array}$ & $\begin{array}{l}\text { Number of } \\
\text { concavities on } \\
\text { each disk }\end{array}$ & $\begin{array}{l}\text { Distribution of } \\
\text { concavities on each } \\
\text { disk }\end{array}$ & $\begin{array}{l}\text { Sintering } \\
\text { temperature }\end{array}$ & $\begin{array}{l}\text { Sample } \\
\text { acronym }\end{array}$ \\
\hline $\begin{array}{l}\text { Role of chemical composition and sintering } \\
\text { temperature on mineralization process }\end{array}$ & HA, $\beta$-ТCP & $\begin{array}{l}\text { Large }(\mathrm{L}, 1.8 \mathrm{~mm}) \\
\text { Medium }(0.8 \mathrm{~mm}) \\
\text { Small }(0.4 \mathrm{~mm})\end{array}$ & 12 & $4 \mathrm{~L}+4 \mathrm{M}+4 \mathrm{~S}$ & $\begin{array}{l}1100^{\circ} \mathrm{C} \\
1200^{\circ} \mathrm{C}\end{array}$ & $\begin{array}{l}\text { HA11_LMS } \\
\text { TCP11_LMS } \\
\text { HA12_LMS } \\
\text { TCP12_LMS }\end{array}$ \\
\hline $\begin{array}{l}\text { Role of concavity size on mineralization } \\
\text { process onset }\end{array}$ & $\mathrm{HA}$ & & & $12 \mathrm{~L}$ or $12 \mathrm{M}$ or $12 \mathrm{~S}$ & $1200^{\circ} \mathrm{C}$ & $\begin{array}{l}\text { HA12_L } \\
\text { HA12_M } \\
\text { HA12_S }\end{array}$ \\
\hline
\end{tabular}


(a)

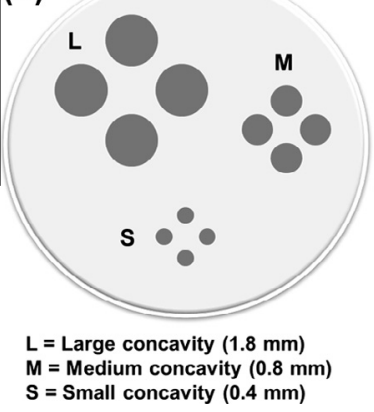

(b)

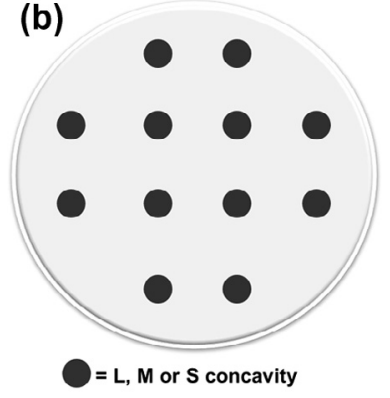

Fig. 1. Schematic representation of disks surface geometry employed in the current study. (a) Schematic distribution of the concavities at the surface of the disks for the preliminary experiment on the effect of chemical composition and sintering temperature on the mineralization process in vitro. Four concavities of each size (1.8 mm (large concavity, L), $0.8 \mathrm{~mm}$ (medium concavity, $\mathrm{M}$ ) and $0.4 \mathrm{~mm}$ (small concavity, S)) were prepared on the surface of the disks; the center-to-center distance was kept at twice the concavity diameter. (b) Scheme of the distribution of the concavities at the surface of the disks for the experiment on the effect of concavity size on mineralization process in vitro. Disks were machined with 12 concavities of the same size (L, M or S).

in SBF for 14 days according to the protocol described above. Additionally, the disks were weighed before and at the end of the experiment, after being gently washed with distilled water and dried at $40{ }^{\circ} \mathrm{C}$ for $24 \mathrm{~h}$.

\subsection{Disk characterization}

The mineralization process on the surface of the CaP disks was followed through SEM, EDS and XRD analyses. Surface morphology and microstructure of the specimens were observed using a scanning electron microscope (JSM6310, JEOL, Japan; operating at an accelerating voltage of $10 \mathrm{kV}$ and a current of $\sim 10 \mathrm{~mA}$ ) after coating the samples with a thin gold layer $(5-10 \mathrm{~nm})$. The elemental analysis was carried out using a scanning electron microscope (Philips XL30, The Netherlands) equipped with an energy-dispersive spectrometer (EDAX, AMETEK Materials Analysis Division, USA) at an accelerating voltage of $10 \mathrm{kV}$, a working distance of $10 \mathrm{~mm}$ and different magnifications. To improve the surface conductivity of the samples, a thin gold layer was deposited on the samples using a common sputtering instrument, which did not affect the measurement of the phosphorus content by EDS. The crystal phase composition of the specimens was characterized by means of a PW3710 Xray diffractometer (Philips, The Netherlands; thin film configuration (fixed angle of incidence of $2.5^{\circ}$ ), with $\mathrm{Cu} K_{\alpha}$ radiation, a voltage of $40 \mathrm{kV}$, a current of $30 \mathrm{~mA}$, a step-size $2 \theta$ of $0.02^{\circ}$, a scanning speed of $0.0052 \theta \mathrm{s}^{-1}$ and a sample time of $4 \mathrm{~s}$ per step).

\subsection{Statistical analysis}

All quantitative data were expressed as mean \pm SD and statistical analyses were performed with GraphPad ${ }^{\circledR}$ Instat 3.05 software (GraphPad Software Inc, San Diego, CA, USA), using one-way analysis of variance (ANOVA) with Tukey Kramer multiple comparison post hoc tests. Results were considered significant at $p<0.05$.

\section{Results}

\subsection{Role of chemical composition and sintering temperature}

The effect of sintering temperature on crystallite size in base materials and sintered disks is presented in Table 2.

Initial evaluations focused on the effect of disk chemical composition and sintering temperature on the mineralization process in vitro. SEM images of the surface of HA and $\beta$-TCP disks containing four large, four medium and four small (LMS) concavities on their surface at different experimental time points are depicted in Fig. 2. After the first week of soaking in SBF, large CaP aggregates up to several hundred micrometers long were observed only within the concavities of HA12_LMS disks, not on the planar surface (Fig. 2a and b). In contrast, only small isolated CaP particles of about 1-5 $\mu \mathrm{m}$ were detected on the planar surface of HA12_LMS disks (outside concavities; Fig. 2c). From the second to the third week of immersion in SBF, a globular CaP layer was formed inside concavities (Fig. 2d), while the planar surface between HA12_LMS disks was homogeneously covered with CaP after 3 weeks of soaking (Fig. 2e), which finally dissolved during the fourth week (Fig. 2f). Analysis of the HA11 samples revealed no formation of such a globular layer, only the presence of $\mathrm{CaP}$ aggregates inside large, medium and small concavities and not at the planar surface at any of the experimental time points (Fig. $2 \mathrm{~g}$, h). Fewer, smaller aggregates were found inside concavities of TCP12_LMS (Fig. 2i,j), whereas hardly any CaP aggregates were detected within the concavities of TCP11_LMS disks (Fig. 2k,1). Further, the surface of TCP11_LMS showed partial degradation after 3 weeks of soaking in SBF, as evidenced by the decreased intensity of machining features inside concavities, whereas the surface of TCP12_LMS was only slightly changed and the surfaces of HA11_LMS and HA12_LMS retained their original appearance.

Calcium quantification analysis revealed that all experimental disks induced calcium uptake during immersion in SBF (Fig. 3). Similar calcium uptake profiles were observed for TCP11_LMS and TCP12_LMS; a significantly $(p<0.001)$ higher calcium uptake was observed for HA11_LMS compared to the calcium uptake of the $\beta$-TCP disks, whereas the largest calcium uptake was observed for HA12_LMS. From the second week onward, a significant difference $(p<0.001)$ between the calcium uptake of HA12_LMS and HA11_LMS was observed. The final cumulative calcium uptake for HA12_LMS was 2-fold higher compared to the uptake for HA11_LMS and 4.6- and 5.4-fold higher compared to the uptake for TCP12_LMS and TCP11_LMS $(p<0.001)$. Calcium assay

Table 2

Crystallite size of the ceramics used, obtained via the Scherrer equation.

\begin{tabular}{lllc}
\hline Material & Temperature $\left({ }^{\circ} \mathrm{C}\right)$ & $2 \theta$ & Crystallite size $(\mathrm{nm})$ \\
\hline HA powder & - & 25,888 & 44.3 \\
$\beta$-TCP powder & - & 25,822 & 46.6 \\
HA & 1100 & 25,920 & 140.6 \\
HA & 1200 & 25,885 & 151.0 \\
$\beta$-TCP & 1100 & 25,801 & 140.5 \\
$\beta$-TCP & 1200 & 25,856 & 262.9 \\
\hline
\end{tabular}




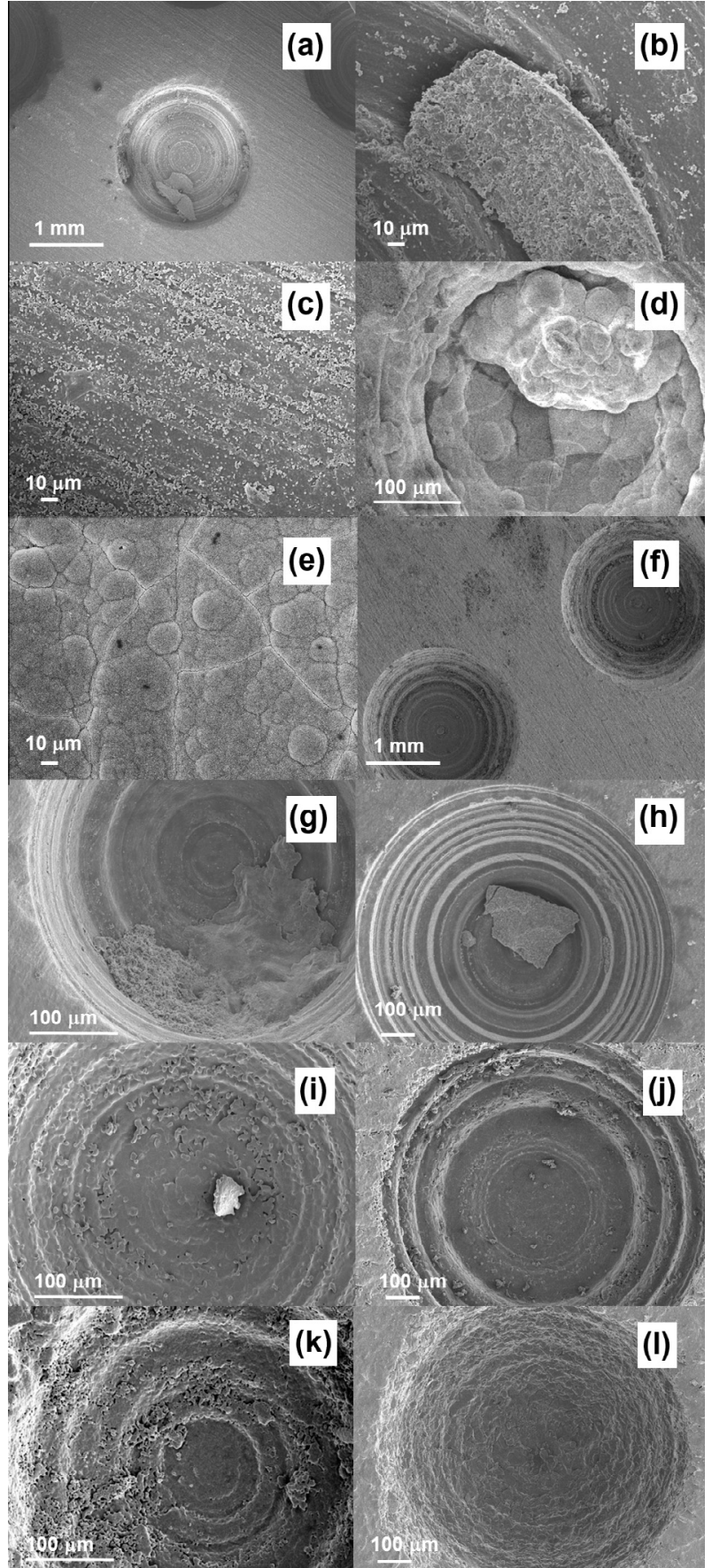

Fig. 2. SEM evaluation of the mineralization process on HA and $\beta$-TCP disks sintered at 1100 and $1200{ }^{\circ} \mathrm{C}$ at different experimental time points. (a) Low-magnification image of the surface of HA12_LMS after week 1, showing macroscopic CaP aggregates inside a large concavity; (b) detail of a CaP aggregate inside a large concavity of HA12_LMS after week 1; (c) planar surface between concavities at the surface of HA12_LMS after week 1; (d) small concavity at the surface of HA12_LMS completely filled by CaP between weeks 2 and 3; (e) planar surface between concavities at the surface of HA12_LMS after week 3; (f) low-magnification image of the surface of HA12_LMS after week 4; (g) CaP aggregate inside a small concavity at the surface of HA11_LMS after week 1 ; (h) CaP aggregate inside a medium concavity at the surface of HA11_LMS after week 3; (i) small CaP aggregate inside a small concavity at the surface of TCP12 LMS after week 1 ; (j) medium concavity surface of TCP12_LMS after week 3; (k) small concavity surface of TCP11_LMS after week 1; (l) medium concavity surface of TCP11_LMS after week 3.

performed on well plates filled only with SBF revealed no calcium uptake on the walls of the well plates at any time point for every disk (data not shown). Due to the observed superior ability to induce surface mineralization for HA12_LMS, further studies were carried out using HA12_LMS disks in order to rationalize the mineralization process and the effect of concavity size on CaP mineralization at the surface.

\subsection{Mineralization process}

SEM and XRD analyses were performed to follow the onset of the mineralization process. SEM images of CaP deposition onto HA12_LMS disks after different immersion times in SBF are presented in Fig. 4. The large aggregates found within concavities after the first week of immersion were composed of micron-sized CaP spherical-like cohesive particles (Fig. 4a). EDS analysis (Fig. 5a) revealed a molar ratio of calcium to phosphorus $(\mathrm{Ca} / \mathrm{P})$ of $1.9-2.0$ for these CaP spherical-like particles. At 2 weeks' immersion in SBF, a globular CaP deposition layer had grown within the concavities that gradually covered the underlying spherical-like CaP particles (Fig. 4b and c). This globular CaP deposition layer was composed of $\sim 50 \mathrm{~nm}$ thick crystals (Fig. $4 \mathrm{~d}$ ) with a $\mathrm{Ca} / \mathrm{P}$ ratio of $1.4-1.5 \mathrm{ar}-$ ranged into a reticular porous structure. EDS analysis (Fig. 5b) revealed a slightly higher atomic percentage of carbon $(\sim 15 \%)$ compared to spherical-like particles (9-10\%), along with small amounts of sodium (1-1.5\%) and magnesium (1-1.1\%) and traces of potassium $(<1 \%)$ and chlorine $(<1 \%)$. The SEM images presented in Fig. 4e and $\mathrm{f}$ show that two small concavities on the same HA12_LMS disk after a 2-week incubation period in SBF are completely filled by the globular CaP. Specifically, in Fig. 4e initial outgrowth of $\mathrm{CaP}$ from the concavity can be detected (black arrows), while in Fig. 4f the globular CaP has already spread over the planar surface close to the concavity (the black arrowheads show the directions of the CaP outgrowth).

XRD diffractograms of HA12_LMS after different SBF immersion times are presented in Fig. 5c. The intensity of all of the main reflection peaks of the diffractogram of HA12_LMS virgin disks decreased from week 0 (before soaking) to week 1 , until a minimum was reached at 2 and 3 weeks. After a 4-week SBF immersion period, the spectrum showed an increase in intensity again. Fig. 5d shows the HA12_LMS diffractograms at $2 \theta$ of $31-33^{\circ}$ ((211), (112) and (300) crystal planes), where the main HA peaks can be found, in order to observe the above-mentioned behavior in more detail. Several secondary reflection peaks were observed at $2 \theta$ of $43-46^{\circ}$ ((113), (400) and (203) crystal planes), corresponding to the CaP deposited on the disks (Fig. 5d, inset). The intensity of these peaks corresponding to the deposited CaP increased from week 0 to week 3, followed by a decrease at week 4 .

\subsection{Role of concavity dimension on SBF mineralization}

In order to quantify the effect of concavity dimension on CaP nucleation in vitro, HA12_L, HA12_M and HA12_S disks were soaked in SBF at $37{ }^{\circ} \mathrm{C}$ for 14 days and characterized for morphology, crystal phase and calcium uptake. The final time point of 14 days was selected in order to study the mineralization process before the spreading of CaP deposits over the planar surface of the disks. Fig. 6a displays representative SEM images of the concavities of HA12_L, HA12_M and HA12_S after a 2-week immersion period in SBF. From detailed SEM investigation, it was observed that nearly all (23 out of 24) of the concavities at the surface of HA12_S disks were filled with spherical-like CaP. In contrast, the concavities at the surface of HA12_M and HA12_L disks were only partially and scarcely filled with CaP deposits, respectively. Similar to the results described above, substantial CaP aggregates were only observed inside concavities and not at the planar surface. This absence of a planar surface CaP layer was confirmed by XRD spectra of HA12_L, HA12_M and HA12_S, which did not show 


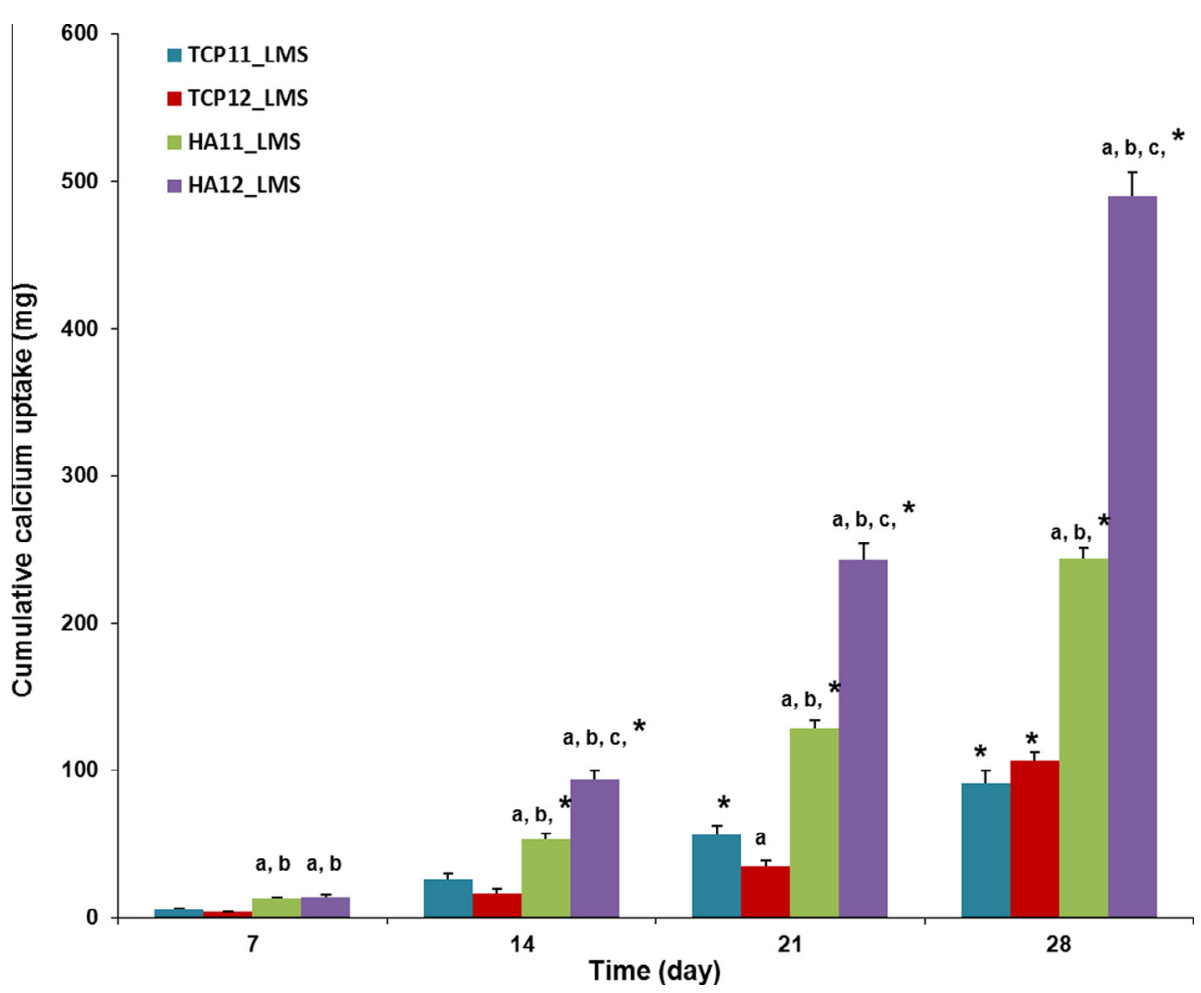

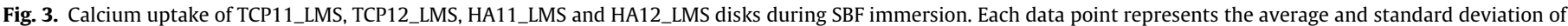

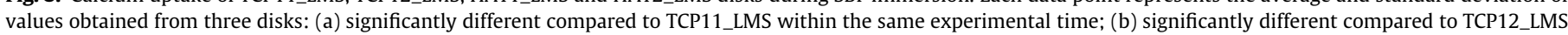

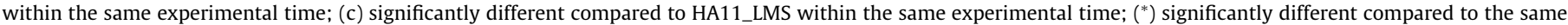
group (same disk type) between one experimental time and the previous one.

differences between the various experimental disks or as compared to the non-soaked HA12 control samples (Fig. 6b).

Differences in the extent of calcium uptake by HA12_L, HA12_M and HA12_S revealed a clear effect of the concavity dimension on the extent of mineralization (Fig. 7a). The calculated amounts of calcium uptake relative to the concavity volume are presented in Table 3. The total calcium uptake of HA12_S was $\sim 1.7$ - and $\sim 1.8$ fold higher compared to HA12_M and HA12_L, respectively. Direct weight measurements of the disks before and after the SBF immersion experiment revealed a weight increase $(\Delta W)$ of $0.36 \%$ for HA12_S, a weight increase in $0.33 \%$ for HA12_M and a weight increase in $0.24 \%$ for HA12_L. The total calcium uptake per volume unit $\left(\mathrm{mg} \mathrm{mm}^{-3}\right.$, calculated by assuming that all CaP was deposited in the concavities) of the concavities of HA12_S (Fig. 7b) was $~ 123-$ and $\sim 10$-fold higher compared to HA12_L (S/L) and HA12_MC $(\mathrm{S} / \mathrm{M})$, respectively, whereas $\Delta W$ per volume unit of the concavities $\left(\mathrm{mg} \mathrm{mm}^{-3}\right.$ ) of HA12_S was $\sim 109$ - and $\sim 7$-fold higher compared to HA12_L (S/L) and HA12_MC (S/M), respectively.

\section{Discussion}

The aim of this study was to evaluate the effect of surface concavities on the surface mineralization of different CaP ceramics in vitro. Our hypotheses were that: (i) concavities prepared at the surface of bioceramic disks could induce surface mineralization in vitro, as surface concavities have been previously demonstrated to induce bone formation at ectopic locations in vivo [13]; and (ii) concavity dimensions affect the extent of surface mineralization. The results of this study clearly demonstrated a strong effect of both disk chemical composition (HA $>\beta$-TCP) and sintering temperature $\left(1200^{\circ} \mathrm{C}>1100^{\circ} \mathrm{C}\right)$ on $\mathrm{CaP}$ deposition from SBF. Further, it was shown that $\mathrm{CaP}$ deposition was initiated exclusively within concavities and not on the planar surface of the disks. Finally, concavity dimensions showed a strong effect on surface mineralization, with a 4 -fold reduction of concavity dimensions resulting in an 123 -fold increase in calcium uptake.

The results of the present study showed that only HA disks sintered at $1200{ }^{\circ} \mathrm{C}$ supported abundant $\mathrm{CaP}$ deposition. Sintering has a strong effect on the density, grain size, porosity, crystalline phases and surface charge of ceramics $[18,19]$. HA sintered at lower temperature is known to be composed of grains of smaller size, thus exhibiting a higher porosity and lower crystallinity compared to HA sintered at higher temperature [19]. Consequently, it can be envisaged that dissolution rates were higher for HA11_LMS compared to HA12_LMS, which in turn limited the extent of nucleation and growth of stable CaP aggregates for HA11_LMS compared to HA12_LMS. Similarly, the faster dissolution of the $\beta$-TCP surface compared to the HA most likely prevented the nucleation of stable CaP nuclei, despite locally (i.e. at the surface) increased ionic concentrations of calcium and phosphate ions; hence it could be inferred that the negative contribution to $\mathrm{CaP}$ nucleation from surface destabilization was higher than the positive contribution due to the local ion concentration, this phenomenon being more important as the sintering temperature decreased. $\beta$-TCP disks sintered at lower temperature were even more unstable, as partial degradation of the surface (evidenced by the loss of regularity of the circular lines following the drilling step) without CaP nucleation on the surface was observed for these disks, corroborating previously reported results [20]. The results of the present study suggest the occurrence of a two-step mineralization process on the HA disks heat treated at $1200^{\circ} \mathrm{C}$, represented by an initial aggregation of spherical-like CaP particles within the concavities (no large aggregates were found on the planar surface of the disks), which were subsequently replaced by a globular $\mathrm{CaP}$ phase 


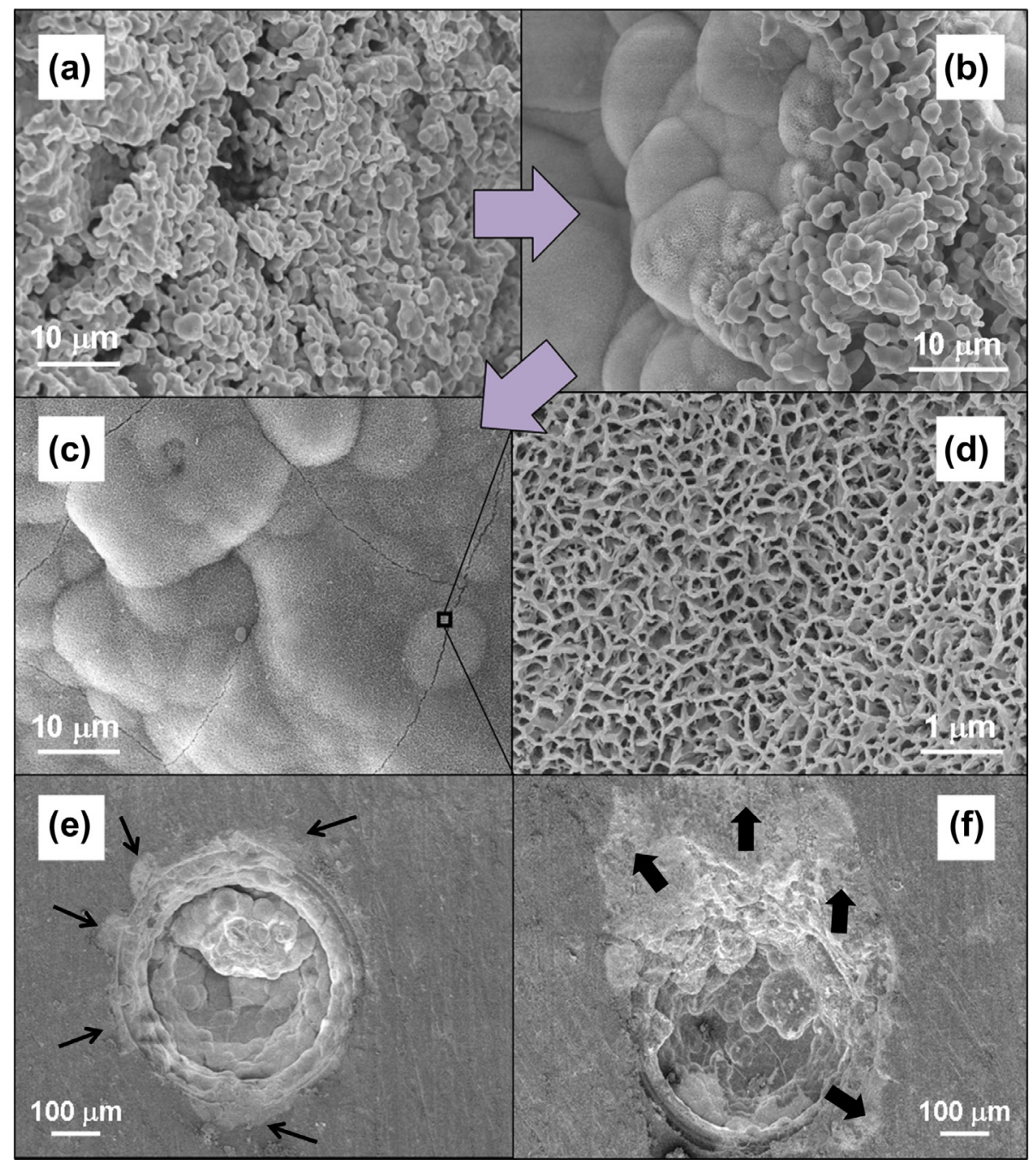

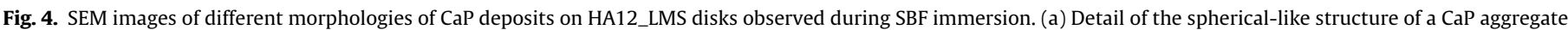

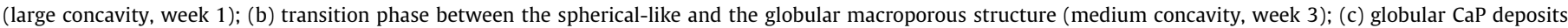

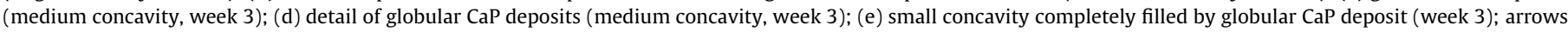

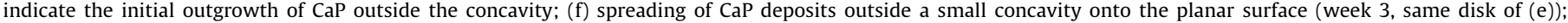
arrowheads indicate the outgrowth direction of the CaP outside the concavity on the planar surface.

consisting of crystals arranged into a reticular macroporous structure, exhibiting a chemical composition which resembled the inorganic phase in bone tissue more closely [21]. Accordingly, semiquantitative EDS data suggested the formation of a Ca-rich $(\mathrm{Ca} / \mathrm{P}$ ratio $1.9-2.0$ ) amorphous calcium phosphate (ACP), eventually replaced by a Ca-poor ( $\mathrm{Ca} / \mathrm{P}$ ratio $\sim 1.4-1.5$ ) carbonate calcium phosphate of general formula $\mathrm{Ca}_{10-x}\left(\mathrm{PO}_{4}\right)_{6-y}\left(\mathrm{CO}_{3}\right)_{y}(\mathrm{OH})_{2}(\mathrm{X})_{y}$, in which a part of $\mathrm{PO}_{4}{ }^{3-}$ was substituted by $\mathrm{CO}_{3}{ }^{2-}$ and a small fraction of $\mathrm{Ca}^{2+}$ was replaced by $\mathrm{X}=\mathrm{Mg}^{2+}$ and $\mathrm{Na}^{+}$and $\mathrm{OH}^{-}$by $\mathrm{Cl}^{-}$ [22]. These findings corroborate several studies reporting the formation of a transient amorphous calcium phosphate phase before the establishment of a globular more crystalline apatitic phase $[18,23]$. A possible explanation resides in the fact that, in $\mathrm{pH} 7.4$ SBF solution, HA possesses a negative surface charge; this negatively charged surface attracts cationic calcium ions from the SBF solution, forming a Ca-rich ACP. Consecutive calcium ions accumulation makes the Ca-rich ACP on the surface of the HA acquire a positive charge. At that stage, the Ca-rich ACP attracts negative phosphate ions in the SBF to form a Ca-poor ACP, which eventually crystallizes into a bone-like apatite by incorporating also other ions from SBF, such as sodium, magnesium, carbonate and chloride
[18]. At the stage of complete filling of small concavities, globular CaP started to spread out from the concavities, ultimately covering the planar surface of the disks completely, as suggested by SEM images like Fig. 4e and $\mathrm{f}$. The formation and subsequent dissolution of the globular CaP coating on the HA12 disk surface could also be monitored by XRD analysis: specifically, the intensity of the main peaks of the HA substrate decreased with soaking time, indicating the establishment of a layer of lower crystallinity on the surface of the disks that limited X-ray diffraction from the more crystalline underlying substrate; after week 4 , the peak intensity increased again toward the starting conditions, which most likely suggests a partial redissolution of the globular CaP layer.

Concavities resemble the hemi-osteonic trenches (from few to several hundreds of micrometers) generated during osteoclastogenesis [24,25]. The effect of concavities on bone growth in ectopic extraskeletal sites in vivo has already been well documented [26], whereas no study attempted to rationalize this phenomenon in vitro. The results of the current study evidenced a very strong templating effect of surface concavities on CaP surface mineralization, whereas no significant CaP deposition occurred on the planar surface. Although no solid explanation could be found to account 

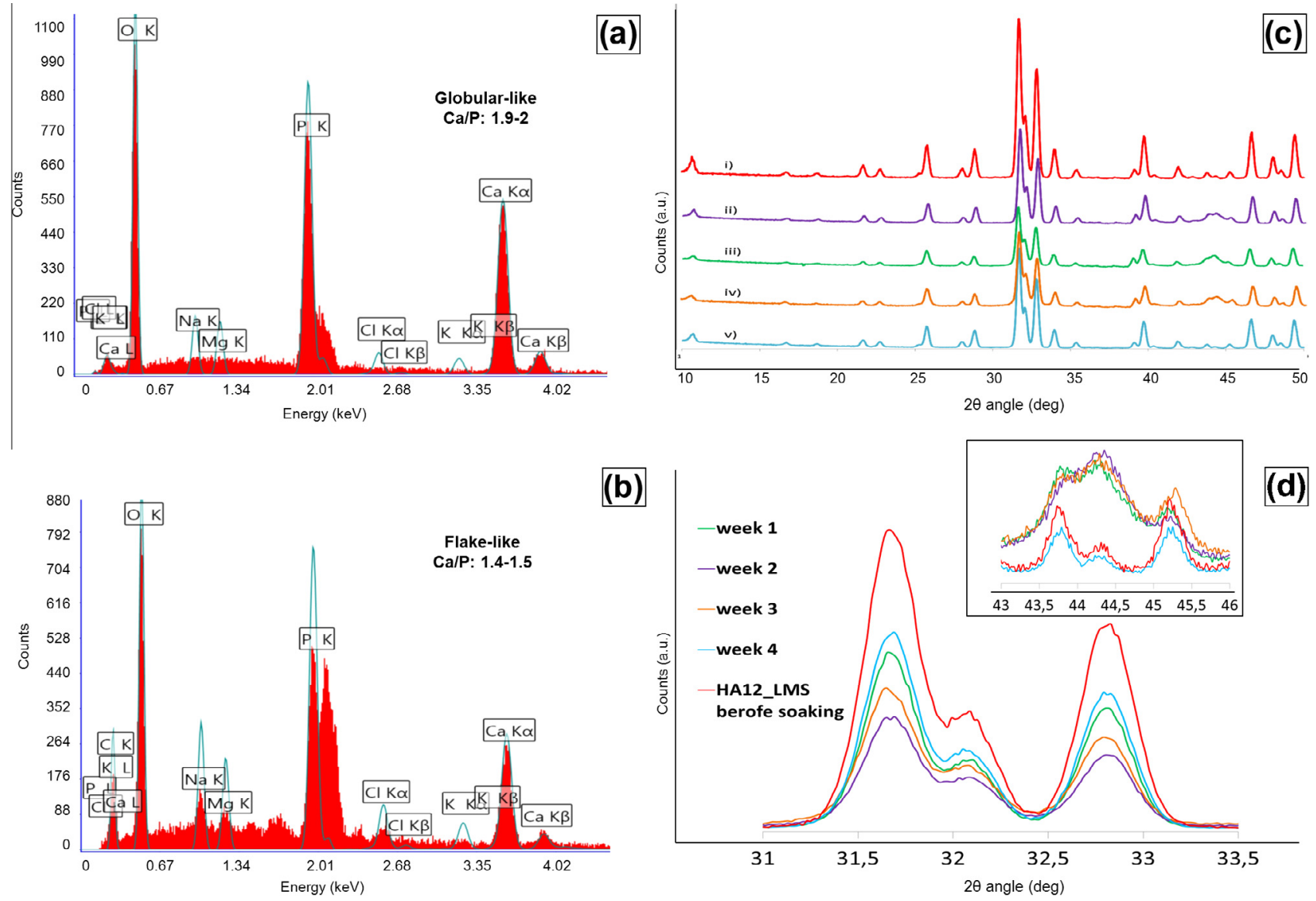

(b)

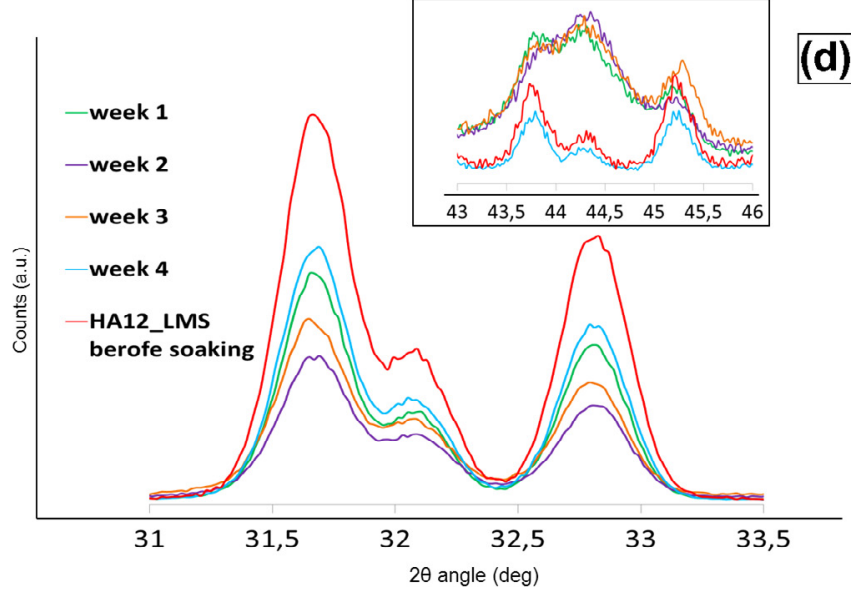

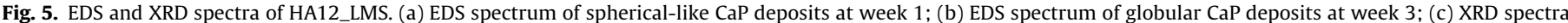

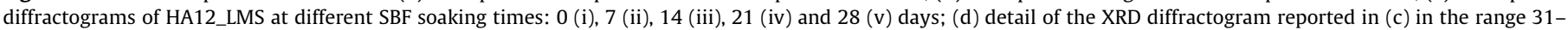
$33.5^{\circ}$; (d, inset) detail of the XRD diffractograms of (c) in the range $43-46^{\circ}$.
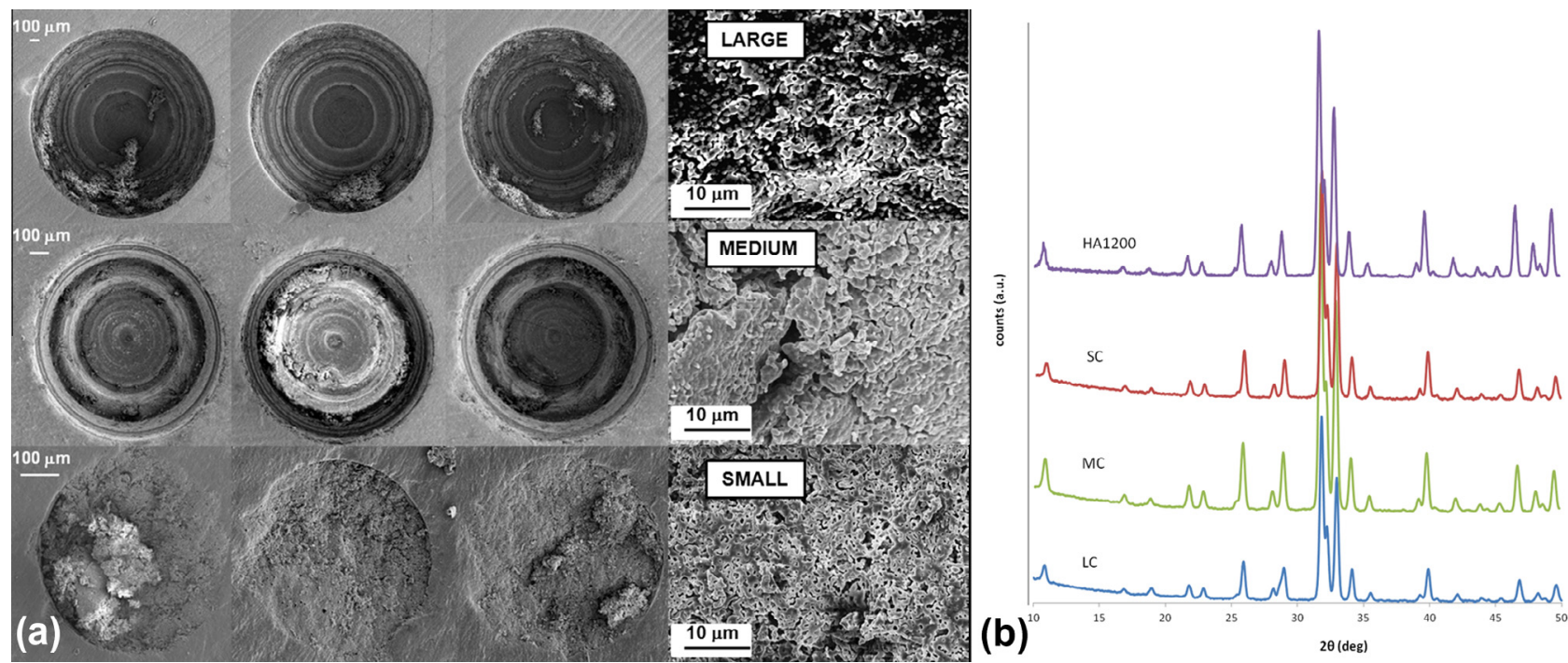

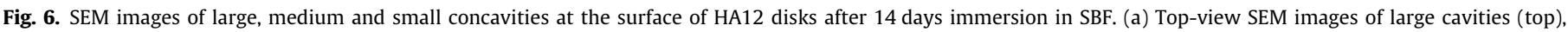

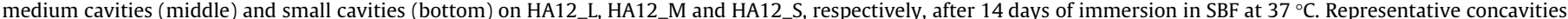

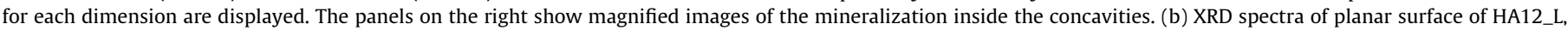
HA12_M and HA12_S (and a reference HA1200 sample).

for this intriguing phenomenon, we speculate that the main contribution to CaP nucleation inside concavities compared to the flat surface can be ascribed to the lower fluid flow rate inside the concavities, which allowed the deposition of calcium and phosphate ions, unlike the more turbulent environment outside concavities: i.e. nuclei deposited on the flat surface redissolved in a shorter time than the time required to reach the critical stable nucleus size. In a recent paper, Kasiteropoulou et al. [27] demonstrated that the 
(a)

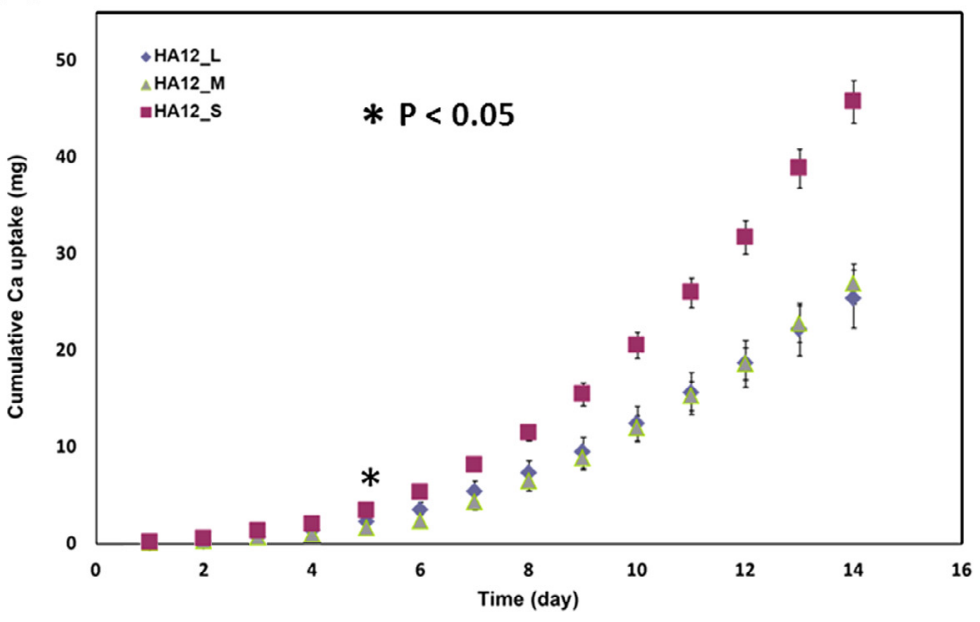

(b)

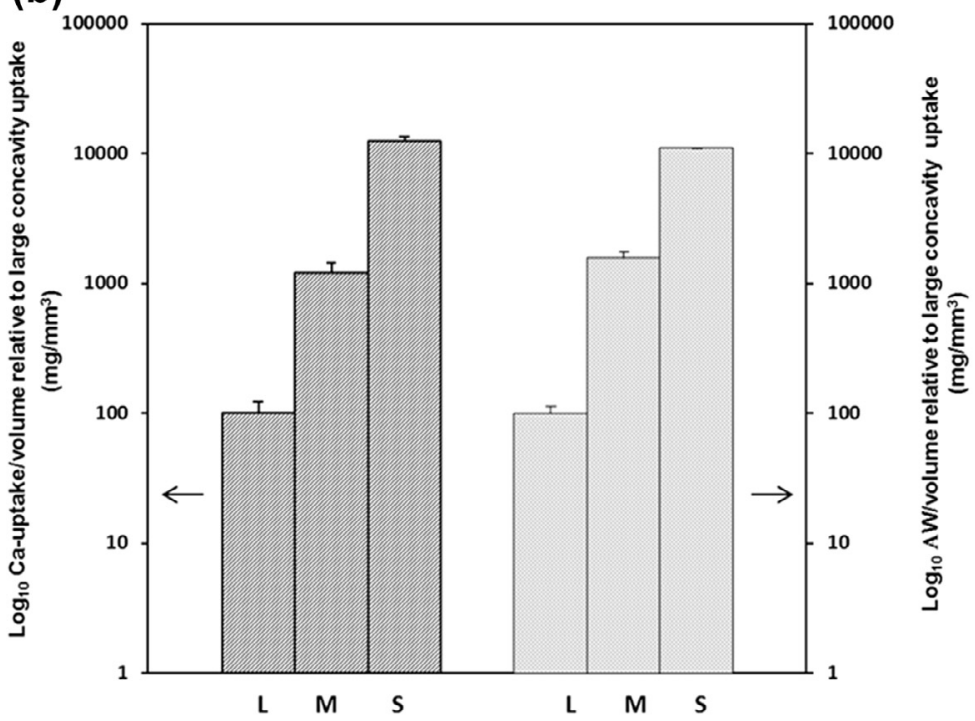

Fig. 7. Quantification of the mineralization process at the surface of HA12 disks after 14 days immersion in SBF. (a) Cumulative calcium uptake for HA12_L (rhombus), HA12_M (triangle) and HA12_S (square) after 14 days immersion in SBF. From day 5 to the end of the experiment, $p<0.05$ between HA12_S and HA12_M or HA12_L. (b) Graph showing the calcium uptake per concavity volume unit of the disks normalized to the uptake of HA12_L (left bars, log scale) and the weight variation for concavity volume unit of the disks normalized to the uptake of HA12_L (right bars, log scale).

Table 3

Quantification of the in vitro mineralization process.

\begin{tabular}{|c|c|c|c|c|c|c|c|c|c|}
\hline & $\begin{array}{l}\text { Concavity } \\
\text { diameter } \\
(\mathrm{mm})\end{array}$ & $\begin{array}{l}\text { Mean disk } \\
\text { surface area } \\
\left(\mathrm{mm}^{2}\right)\end{array}$ & $\begin{array}{l}\text { SBF volume to } \\
\text { surface area } \\
\left(\mathrm{mL} / \mathrm{mm}^{2}\right)\end{array}$ & $\begin{array}{l}\text { Volume of } 1 \\
\text { concavity } \\
\left(\mathrm{mm}^{3}\right)\end{array}$ & $\begin{array}{l}\text { Volume of } 12 \\
\text { concavities } \\
\left(\mathrm{mm}^{3}\right)\end{array}$ & $\begin{array}{l}\text { Total Ca } \\
\text { uptake } \\
(\mathrm{mg})\end{array}$ & $\begin{array}{l}\text { Ca uptake per } \\
\text { concavity volume } \\
\left(\mathrm{mg} / \mathrm{mm}^{3}\right)\end{array}$ & $\begin{array}{l}\Delta \mathrm{W} \\
(\mathrm{mg})\end{array}$ & $\begin{array}{l}\Delta \mathrm{W} \text { per concavity } \\
\text { volume }\left(\mathrm{mg} / \mathrm{mm}^{3}\right)\end{array}$ \\
\hline LC & $1.79 \pm 0.03$ & $376 \pm 39$ & $0.027 \pm 0.003$ & $1,5 \pm 0.1$ & $18 \pm 2$ & $25 \pm 3$ & $1.4 \pm 0.3$ & $5.0 \pm 0.2$ & $0.28 \pm 0.04$ \\
\hline MC & $0.80 \pm 0.02$ & $352 \pm 35$ & $0.028 \pm 0.003$ & $0,13 \pm 0.01$ & $1.6 \pm 0.1$ & $27 \pm 2$ & $17 \pm 3$ & $7.1 \pm 0.2$ & $4.4 \pm 0.5$ \\
\hline SC & $0.44 \pm 0.01$ & $348 \pm 34$ & $0.029 \pm 0.003$ & $0,022 \pm 0.001$ & $0.27 \pm 0.01$ & $46 \pm 2$ & $172 \pm 14$ & $8.1 \pm 0.2$ & $30.5 \pm 0.9$ \\
\hline
\end{tabular}

$\mathrm{LC}=$ large concavity; $\mathrm{MC}=$ medium concavity; $\mathrm{SC}=$ small concavity; $\Delta \mathrm{W}=(\text { Weight })_{\text {final }}-(\text { Weight })_{\text {initial }}$.

velocity of the fluid inside microchannels with protrusions was lower inside the cavities (i.e. between two protrusions) than on the flat surface, and the higher the protrusion the lower the velocity. They also studied pressure maps inside microchannels, the pressure being fluid pressure that was strictly related to the density of the particles (calcium and phosphate ions in our case) inside the fluid. The authors found that inside the cavities "there is a high pressure region (high particle density region) whose length depends on the protrusion size, being larger as the protrusion size decreases". Even if extrapolation of this behavior from the micron to the submillimeter regime cannot be underestimated, we found that smaller concavities provided lower flows and higher 
particulate density compared to larger concavities, which in turn led to an accelerated increase in local ionic concentrations of $\mathrm{Ca}^{2+}$ and $\mathrm{PO}_{4}{ }^{3-}$ compared to larger concavities, where higher flow rates are expected due to the larger size. Finally, since mineralization is a unique process involved in bone tissue formation, the data presented herein represent a first attempt to link mineralization to osteoinduction, which by itself is a completely novel approach.

\section{Conclusions}

The results of the present study showed that the in vitro surface mineralization process of CaP ceramics with surface concavities starts preferentially within the concavities and not on the planar surface of the ceramics, indicating a strong templating effect of the concavities on CaP surface mineralization. Further, concavity size was revealed to be an extremely effective parameter for controlling the extent of in vitro surface mineralization, with small concavity dimensions resulting in considerably more surface mineralization.

\section{Acknowledgement}

This research forms part of the Project P2.04 BONE-IP of the research program of the BioMedical Materials Institute, co-funded by the Dutch Ministry of Economic Affairs, Agriculture and Innovation.

\section{Appendix A. Figures with essential colour discrimination}

Certain figures in this article, particularly Figs. 3-7, are difficult to interpret in black and white. The full colour images can be found in the on-line version, at doi: http://dx.doi.org/10.1016/j.actbio. 2013.10 .026

\section{References}

[1] Rezwan K, Chen QZ, Blaker JJ, Boccaccini AR. Biodegradable and bioactive porous polymer/inorganic composite scaffolds for bone tissue engineering. Biomaterials 2006;27:3413-31.

[2] Dorozhkin SV. Bioceramics of calcium orthophosphates. Biomaterials 2010;31:1465-85.

[3] Tampieri A, Sprio S, Sandri M, Valentini F. Mimicking natural biomineralization processes: a new tool for osteochondral scaffold development. Trends Biotechnol 2011;29:526-35.

[4] Chai YC, Carlier A, Bolander J, Roberts SJ, Geris L, Schrooten J, et al. Current views on calcium phosphate osteogenicity and the translation into effective bone regeneration strategies. Acta Biomater 2012;8:3876-87.

[5] Ozdemir T, Higgins AM, Brown JL. Osteoinductive biomaterial geometries for bone regenerative engineering. Curr Pharm Des 2013;19:3446-55.
[6] Yuan HP, Fernandes H, Habibovic P, de Boer J, Barradas AMC, de Ruiter A, et al. Osteoinductive ceramics as a synthetic alternative to autologous bone grafting. Proc Natl Acad Sci USA 2010;107:13614-9.

[7] Habibovic P, Sees TM, van den Doel MA, van Blitterswijk CA, de Groot K. Osteoinduction by biomaterials - physicochemical and structural influences. J Biomed Mater Res Part A 2006;77A:747-62.

[8] Tampieri A, Celotti G, Landi E. From biomimetic apatites to biologically inspired composites. Anal Bioanal Chem 2005;381:568-76.

[9] Schouten C, Meijer GJ, van den Beucken J, Spauwen PHM, Jansen JA. Effects of implant geometry, surface properties, and TGF-beta 1 on peri-implant bone response: an experimental study in goats. Clin Oral Impl Res 2009;20:421-9.

[10] Li B, Liao XL, Zheng L, Zhu XD, Wang Z, Fan HS, et al. Effect of nanostructure on osteoinduction of porous biphasic calcium phosphate ceramics. Acta Biomater 2012;8:3794-804.

[11] Prodanov L, Lamers E, Domanski M, Luttge R, Jansen JA, Walboomers XF. The effect of nanometric surface texture on bone contact to titanium implants in rabbit tibia. Biomaterials 2013;34:2920-7.

[12] Graziano A, d'Aquino R, Cusella-De Angelis MG, Laino G, Piattelli A, Pacifici M, et al. Concave pit-containing scaffold surfaces improve stem cell-derived osteoblast performance and lead to significant bone tissue formation. PLoS One $2007 ; 2$.

[13] Ripamonti U, Roden LC, Ferretti C, Klar RM. Biomimetic matrices self-initiating the induction of bone formation. J Craniofac Surg 2011;22:1859-70.

[14] Ripamonti U, Roden LC, Renton LF. Osteoinductive hydroxyapatite-coated titanium implants. Biomaterials 2012;33:3813-23.

[15] Ripamonti U. Biomimetism, biomimetic matrices and the induction of bone formation. J Cell Mol Med 2009;13:2953-72.

[16] Scarano A, Degidi M, Perrotti V, Degidi D, Piattelli A, Iezzi G. Experimental evaluation in rabbits of the effects of thread concavities in bone formation with different titanium implant surfaces. Clin Impl Dent Rel Res 2013. http:// dx.doi.org/10.1111/cid.12033.

[17] Kokubo T, Takadama H. How useful is SBF in predicting in vivo bone bioactivity? Biomaterials 2006;27:2907-15.

[18] Kim HM, Himeno T, Kokubo T, Nakamura T. Process and kinetics of bonelike apatite formation on sintered hydroxyapatite in a simulated body fluid. Biomaterials 2005;26:4366-73.

[19] Mezahi FZ, Oudadesse H, Harabi A, Lucas-Girot A, Le Gal Y, Chaair H, et al. Dissolution kinetic and structural behaviour of natural hydroxyapatite vs. thermal treatment. J Therm Anal Calorim 2009;95:21-9.

[20] Xin RL, Leng Y, Chen JY, Zhang OY, A comparative study of calcium phosphate formation on bioceramics in vitro and in vivo. Biomaterials 2005:26:6477-86.

[21] Landi E, Tampieri A, Celotti G, Langenati R, Sandri M, Sprio S. Nucleation of biomimetic apatite in synthetic body fluids: dense and porous scaffold development. Biomaterials 2005;26:2835-45.

[22] Haobo Pan H, Zhao X, Darvell B, Lu W. Apatite-formation ability - predictor of "bioactivity"? Acta Biomater 2010;6:4181-8.

[23] Kim S, Ryu H, Shin H, Jung HS, Hong KS. In situ observation of hydroxyapatite nanocrystal formation from amorphous calcium phosphate in calcium-rich solutions. Mater Chem Phys 2005;91:500-6.

[24] Ripamonti U, Crooks J, Kirkbride AN. Sintered porous hydroxyapatites with intrinsic osteoinductive activity: geometric induction of bone formation. S Afr J Sci 1999;95:335-43.

[25] Parfitt AM, Mundy GR, Roodman GD, Hughes DE, Boyce BF. A new model for the regulation of bone resorption, with particular reference to the effects of bisphosphonates. J Bone Miner Res 1996;11:150-9.

[26] Ripamonti U, Tsiridis E, Ferretti C, Kerawala CJ, Mantalaris A, Heliotis M. Perspectives in regenerative medicine and tissue engineering of bone. $\mathrm{Br} J$ Oral Maxillofac Surg 2011;49:507-9.

[27] Kasiteropoulou D, Karakasidis TE, Liakopoulos A. Mesoscopic simulation of fluid flow in periodically grooved microchannels. Comput Fluids 2013;74: 91-101. 